\title{
Endoscopically guided thoracoscopic esophagectomy for stricture in a child
}

\author{
Marcus M. Malek · Sohail R. Shah • \\ Aviva L. Katz · Timothy D. Kane
}

Received: 29 December 2008/Accepted: 1 May 2009/Published online: 11 June 2009

(C) Springer Science+Business Media, LLC 2009

\begin{abstract}
Purpose Caustic ingestion is a common cause for acquired esophageal strictures in children. Thoracoscopic esophagectomy can be very useful in this setting, particularly for short segments of disease [1-4]. Thus far, the use of endoscopy to guide resection margins has not been described.

Methods A 6-year-old boy developed a tight, short esophageal stricture from a lye ingestion injury at the age of 4 years. He had a gastrostomy tube placed at the time for supplemental feedings and subsequently failed attempts at antegrade and retrograde esophageal dilatation. This video demonstrates an endoscopically guided (endoscopes simultaneously passed retrograde via the gastrostomy and antegrade through the oropharynx) thoracoscopic esophagectomy and primary anastomosis management of the stricture.

Methods In the left lateral decubitus position, four 5-mm ports were placed in the right chest in the fifth intercostal space, anterior-axillary line; sixth intercostal space, midaxillary line; fourth intercostal space, midaxillary line; and seventh intercostal space, posterior axillary line. A 5-mm $30^{\circ}$ Storz $^{\circledR}$ telescope and $4.9-\mathrm{mm}$ and 9.6-mm Olympus ${ }^{\circledR}$
\end{abstract}

Electronic supplementary material The online version of this article (doi:10.1007/s00464-009-0545-9) contains supplementary material, which is available to authorized users.

M. M. Malek · S. R. Shah · A. L. Katz · T. D. Kane $(\square)$ Division of Pediatric General and Thoracic Surgery, Children's Hospital of Pittsburgh, University of Pittsburgh Medical Center, 3705 Fifth Ave., 4A-485, Pittsburgh, PA 15213, USA

e-mail: kanetd@upmc.edu

M. M. Malek

e-mail: marcus.malek@chp.edu endoscopes were used. The area of esophageal stricture was identified using the endoscopes and thoracoscopically dissected circumferentially. The vagus nerves were identified and circumferentially freed from the strictured esophageal segment. Primary resection and anastomosis was performed using intracorporeal sutures and then tested for leak using the endoscope via the gastrostomy site.

Results Esophagram on postoperative day (POD) 7 revealed no leak and a widely patent anastomosis. He was discharged home on a soft diet on POD 8 and continues to feed orally over 1 year following his operation.

Conclusion As demonstrated by our video, endoscopy is a useful adjunct in the performance of a thoracoscopic esophagectomy for short esophageal stricture. It is particularly helpful because it provides direct visualization of the compromised lumen and allows for a more precise resection.

Keywords Pediatric Endoscopy · Thoracoscopy · Esophagectomy $\cdot$ Stricture

\section{References}

1. Cury EK, Schraibman V, De Vasconcelos Macedo AL, Echenique LS (2001) Thoracoscopic esophagectomy in children. J Pediatr Surg 36:E17

2. Kane TD, Nwomeh BC, Nadler EP (2007) Thoracoscopic-assisted esophagectomy and laparoscopic gastric pull-up for lye injury. JSLS 11:474-480

3. Nwomeh BC, Luketich JD, Kane TD (2004) Minimally invasive esophagectomy for caustic esophageal stricture in children. J Pediatr Surg 39:e1-e6

4. Senkowski CK, Adams MT, Beck AN, Brower ST (2006) Minimally invasive esophagectomy: early experience and outcomes. Am Surg 72:677-683 